\title{
EDITORIAL
}

\section{Studying brain receptor function: a neuroendocrine approach}

Timothy G Dinan, PhD, MD, Department of Psychological Medicine, St. Bartholomew's Hospital, London EC1.

\begin{abstract}
A significant component of psychiatric practice relates to the management of patients with behavioural disturbance whose aetiology lies in the subtle alteration of brain biochemistry. The major handicap in assessing such patients, both from a clinical and a research point of view has been a lack of suitably sophisticated technology for studying brain function. Despite significant improvements in imaging technique and the development of positron emission tomography we are still lacking tools which assess brain receptor functioning. The neuroendocrine axis provides us with the means of assessing specific neurotransmitters in a safe and relatively inexpensive way. Such an approach is now widely used in research and has considerable potential within a clinical setting.

The fact that classic monoamine neurotransmitters are implicated both in affective disorders and schizophrenia and at the same time control hypothalmicanterior pituitary function provides the basis for many psychoneuroendocrine investigations. The stimulation of certain central neurotransmitter systems results in the elevation of anterior pituitary hormones. If a pharmacologically selective drug is used, the rise in the anterior pituitary hormone gives some index of the integrity of the neurotransmitter pathway and the sensitivity of its receptor system. This approach is heavily dependent on the development of selective drugs for challenging specific receptor systems. As there are a myriad of potential confounding variables it is essential that there be rigorous control over such factors as gender, age, psychotropic drug exposure, weight loss etc.

The release of growth hormone $(\mathrm{GH})$ from the anterior pituitary is under the control of 2 peptides, namely growth hormone releasing hormone (GHRH) and somatostatin (SS). Noradrenaline acting via the GHRH containing neurones stimulates the release of $\mathrm{GH}(1,2)$. We now know that the stimulated release of GH through this mechanism is significantly blunted in patients with major depression $(3,4,5)$. When
\end{abstract}

sone suppression and noradrenergic mediated $\mathrm{GH}$ release are both investigated in depressed patients, those subjects who show dexamethasone non-suppression are more likely to demonstrate blunted $\mathrm{GH}$ release than those with normal dexamethasone responses (5). Acetylcholine (ACh) stimulates growth hormone release via the SS method (6). It is now clear that depressed patients show enhanced release when their cholinergic system is challenged with pyridostigmine (7). Overall therefore, depressed patients seem to have a downregulation or under activity of their NA receptors and an up-regulation or over-activity of their $\mathrm{ACh}$ receptors.

GH release is also under GABAergic control. In a study of patients with major depression baclofen the GABA-B agonist was used to induce GH release. Baclofen $(20 \mathrm{mg})$ significantly elevated $\mathrm{GH}$ levels in all healthy subjects but a blunting of response was seen in those patients with major depressive illness. The finding indicates diminished responsivity of the GABA$B$ receptor system in depression (7a).

The release of prolactin from the anterior pituitary is under the inhibitory control of dopamine (DA) which acts directly on the lactotrophs of the pituitary. The release of prolactin is stimulated by serotonin $(8,9)$. There is now unequivocal evidence to indicate that 5-HT mediated prolactin release is blunted in major depression $(10,11)$. Such blunting has been demonstrated with a wide variety of probe drugs including 1-tryptophan and fenfluramine. The abnormality is however not entirely specific to depression as patients with obsessive compulsive disorder and sociopathic personality disorder also demonstrate such blunting even in the absence of mood disturbance $(12,13)$.

The first evidence to emerge that central DA receptors might in some way control GH release was demonstrated by the administration of 1-dopa which led to an increase in GH levels (14). GH responses to the DA agonist apomorphine have been reported to be greater in patients with first rank symptoms of schizophrenia, but to be blunted in those patients with significant egative symptoms such as emotional flattening and

Editor in Chief: Mark Hartman (Dublin). Editors: Timothy Dinan (London), Roy McClelland (Belfast). Deputy Editor: Brian O'Shea (Dublin). Associate Editors: Ken Brown (Belfast), Patricia Casey (Dublin), Anthony Clare (Dublin), Stephen Cooper (Belfast), Thomas Fahy (Galway), Michael Fitzgerald (Dublin), Michael Kelleher (Cork), David King (Belfast), Brian Leonard (Galway), Aidan McGennis (Dublin), Ciaran O'Boyle (Dublin), Eadbhard O'Callaghan (Dublin), Art O'Connor (Dublin), Ethna O'Gorman (Belfast), lan Pullen (Edinburgh), David Sheehan (Tampa), Philip Snaith (Leeds), Hugh Staunton (Dublin), John Waddington (Dublin), Richard Williams (Calgary). Statistical Editor: Leslie Daly (Dublin). Deputy Statistical Editor: Ronan Conroy (Dublin). 
social withdrawal $(15,16)$.

The very complex neurotransmitter control of such hormones as $\mathrm{GH}$ and prolactin provides a window to the biology of neuro-behavioural disturbance. As a tool psychoneuroendocrinology is of relevance not just to the researcher but to the practicing psychiatrist as well.

\section{References}

1. Lovinger R, Holland J, Kaplan S, et al. Pharmacological evidence for stimulation of growth hormone secretion by a central noradrenergic system in dogs. Neuroscience 1976; 1: 443-50.

2. Katakami H, Kato Y, Matsushita N, Imura H. Effects of neonatal treatment with monosodium glutamate on growth hormone release induced by clonidine and prostaglandin $\mathrm{E} 1$ in conscious male rats. Neuroendocrine 1984; 38: 1-5.

3. Checkley SA, Slade AP, Shur P. Growth hormone responses and other responses to clonidine in patients with endogenous depression. Br J Psychiatry 1981; 138: 51-5.

4. Charney DS, Henninger GR, Sternberg DE. Alpha 2 adrenergic receptor sensitivity and the mechanism of action of antidepressant therapy. Br J Psychiatry 1983; 142: 265-75.

5. Dinan TG, Barry S. Responses of growth hormone to desimpramine in endogenous and non-endogenous depression. $\mathrm{Br} \mathrm{J}$ Psychiatry 1990; 156: 680-4.

6. Casaneuva FF, Betti R, Cella SG, et al. Effects of agonists and antagonists of cholinergic neurotransmission on growth hormone release in the dog. Acta Endocrinol 1983; 103: 15-20.

7. O'Keane V, O'Flynn K. Lucey J. Dinan TG. Pyridostigmine induced growth hormone responses in healthy and depressed subjects: evidence for cholinergic supersensitivity in depression. Psychol Med 1992; 22: 55-60. 7a. O'Flynn K, Dinan TG. Baclofen induced growth hormone release in major depression: relationship to dexamethasone suppressor status. Am J Psychiatry. In press.

8. Charney DS, Henninger JR, Sternberg DE. Serotonin function and mechanism of action of antidepressant treatment: effects of amitriptyline and desipramine. Arch Gen Psychiatry 1984; 41 : $359-65$.

9. O'Keane V, O'Hanlon M, Webb M. Dinan TG. dfenfluramine/prolactin response throughout the menstrual cycle: evidence for an oestrogen induced alteration. Clin Endocrinol 1991; 34: 289-92.

10. Coccaro E, Siever LJ, Kalar HM, et al. Serotoninergic studies in patients with affective and personality disorders. Arch Gen Psychiatry 1989; 46: 587-99.

11. O'Keane V, Dinan TG. Prolacting and cortisol responses to dfenfluramine in major depression: evidence for diminished responsivity of central serotoninergic function. Am J Psychiatry 1991; 148: 1009-15.

12. O'Keane V, Maloney E, O'Neill $\mathrm{H}$, et al. Blunted prolactin responses to d-fenfluramine in sociopathy: evidence for subsensitivity of central serotoninergic function. Br J Psychiatry 1992; 160: 643-6.

13. Lucey JV, O'Keane V, Butcher G, et al. Prolactin and cortisol responses to $\mathrm{d}$-fenfluramine in obsessive compulsive disorder: a comparison with depressives and healthy controls. Br J Psychiatry 1992; 161: 512-7.

14. Boyd AE, Lebovitz HE, Pfeiffer JB. Stimulation of growth hormone secretion by 1-dopa. N Engl J Med 1970; 183: 1425-9.

15. Whalley LJ, Christie JE, Brown S, Arbuthontt GW, Schneider's first rank symptoms of schizophrenia: an association with increased growth hormone response to apomorphine. Arch Gen Psychiatry $1984 ; 41: 103-4$

16. Ferrier N, Johnstone EC, Crow TJ, Rodriguez IR. Anteriro pituitary hormone secretion in chronic schizophrenics. Arch Gen Psychiatry 1986; 4: 755-61.

\section{GUIDELINES FOR AUTHORS}

The Journal's aim is to publish original scientific contributions in psychiatry, psychological medicine (including surgery and obstetrics), and related basic sciences (neurosciences, biological, psychological, and social sciences). Its scope includes any subspecialties of the above, e.g.: behavioural pharmacology, biological psychiatry, child and adolescent psychiatry, mental handicap, forensic psychiatry, psychotherapies, psychiatry of old age, epidemiology, rehabilitation, psychometrics, substance misuse, sexual studies, linguistics, and the history, philosophy, and economics of psychiatry.

The Journal will accept original papers, clinical case reports, brief research reports, review articles, perspective articles, historical papers, editorials, practice reviews (medical audits), letters to the editor, and book reviews. Review articles are usually invited. Original data papers receive top priority for speedy publication.

Manuscripts should be prepared in accordance with the guidelines of the International Committee of Medical Journal Editors (I). The page following the title page should carry an Abstract followed by a list of 3-10 Key Words or short phrases drawn, if possible, from the medical subject headings (MeSH) list of Index Medicus. The Title, Key Words, and Abstract should be chosen to help future literature searchers.

The Abstract, up to 150 words for an unstructured or 250 words for a structured abstract (2), should state specifically the main purposes, procedures, findings, and conclusions of the study, emphasizing what is new or important. For original papers, brief research reports, medical audits, and review articles a structured abstract (2) is required, using the headings Objective, Method, Results (Findings for review articles), and Conclusions. Under the Abstract heading of Method, include wherever applicable the study design, setting, patients/participants (selection criteria, description), interventions, observational and analytical methods and main outcome measures. (For review articles specify the methods of literature search and selection). Under the Abstract heading of Results, give the most important specific data together with their statistical significance.

Timely references should highlight the study's relevance to current research or clinical practice. References to journal articles (1-3) and to books (4-6) illustrate the "Vancouver" style (I), with journal titles abbreviated as in Index Medicus.

The "Uniform requirements for manuscripts submitted to biomedical journals" (I) has two paragraphs on statistical guidelines. These have been explained and elaborated by Bailar and Mosteller (3).

Figures should be on professional sharp, glossy black and white photographic prints. The figures themselves should be $31 / 4$ inches wide - i.e. the width of a column of print (in some cases, 7 inches wide, to fit into two columns). Do not include the detailed legends in the photographs of the figures.

All materials sent for publication should be accompanied by a covering letter signed by all the authors, and such material will become the property of the Journal until, and if, publication is refused. Materia so referred should not be sent elsewhere for publication. One copy of the manuscript should be retained by the author(s) for reference, and four copies of the manuscript and covering letter, one of these being the original, should be sent to The Editor, Irish Journal of Psychological Medicine, St. Brendan's Hospital, Rathdown Road, Dublin 7, Ireland.

All contributions are peer-reviewed by three anonymous assessors, and where relevant by the deputy statistical editor whom authors may contact for help. Assessments will be sent to the corresponding author usually within six weeks. Where revisions are sought prior to publication, authors are advised to return their revision in quadruplicate, incorporating any suggestions which they agree would improve their paper. The covering letter should respond to each comment, numbered, of each assessor, indicating where the revision deals with it, or why the authors disagree or cannot incorporate it. Each assessor will then receive the authors' revision, covering letter, and the previous comments of the other assessors. After the assessors' further comments have been received the senior editors will make the final decision, including priority and time of publication, and the right to style and if necessary shorten material for publication.

References

1. International Committee of Medical Journal Editors. Uniform requirement for manuscripts submitted to biomedical journals. BMJ 1991; 302: 338-41.

2. Haynes RB, Mulrow CD, Huth EJ, Altman DG, Gardner MJ. More informative abstracts revisited. Ann Intern Med 1990; 113: 69-76.

3. Bailar JC, Mosteller F Guidelines for statistical reporting in articles for medical journals. Ann Intern Med 1988 Feb; 108(2): 266-73.

4. Daly LE, Bourke GJ, McGilvray J. Interpretation and uses of medical statistics. 4th ed. Oxford: Blackwell Scientific Publications, 1991; 428-31.

5. Gardner MJ, Altman DG, editors. Statistics with confidence - confidence intervals and statistical guidelines. London: British Medical Journal, 1989: 103, 105. [Note: British Medical Journal here is the publisher of a book, not the journal BMJ]

6. American Psychiatric Association. Diagnostic and statistical manual of mental disorders. 3rd rev ed. Washington DC: American Psychiatric Association, 1987. 